\title{
The Pathogenesis of Duodenal Ulcer and the Role of Helicobacter pylori in This Disease: A Systematic Review
}

Simon Xin Min Dong ${ }^{*}$ Katelynn Jean Rowe, and Connie Ching Yuen Chang

International Institute of Consciousness Science ${ }^{\circledR}$, Ottawa, ON, K1H8L1, Canada

${ }^{*}$ Correspondence author at: simondong@outlook.com; Apoptosis Research Center of Children's Hospital of Eastern Ontario, Faculty of Medicine, University of Ottawa, Ottawa, ON, K1H8L1, Canada

\section{Abstract}

Background: The pathogenesis of duodenal ulcer has never been explained although the first description of this disease in medical literature appeared in 1817. Marshall et al. concluded that Helicobacter pylori was the most important etiological factor for duodenal ulcer in 1988, but the etiology based on this bacterium is controversial and how the bacterial infection leads to ulceration is presently unknown.

Objectives: This study aims to identify the cause of duodenal ulcer, address the controversial issues surrounding Helicobacter pylori, elucidate the roles of gastric acid, and describe the pathological process of duodenal ulceration.

Methods: First, a comprehensive systematic review on peptic ulcers (including gastric ulcer and duodenal ulcer) was conducted and the results were summarized. Second, a recently published causal relationship was employed to identify the etiology of peptic ulcers. Third, novel concepts and methods were applied to analyze the existing data on duodenal ulcer.

Results: The etiology of duodenal ulcer and the roles of Helicobacter pylori and gastric acid in this disease were identified. The controversies surrounding Helicobacter pylori were addressed, and many characteristics and phenomena/observations of duodenal ulcer were elucidated. The pathological process of duodenal ulceration was described.

Conclusion: Existing data accumulated over the past 300 years was sufficient, when analyzed using novel concepts, to understand the pathogenesis of duodenal ulcer. Duodenal ulcer is not an infectious disease caused by the infection of Helicobacter pylori, but a psychosomatic disease triggered by psychological stress. Helicobacter pylori plays a secondary role in only the late phase of duodenal ulceration.

Keywords: duodenal ulcer; pathogenesis; gastric acid; helicobacter pylori; psychosomatic disease; psychological stress 


\section{Introduction}

Over the past 300 years, many theories have been proposed to explain the pathogenesis of peptic ulcers (including duodenal ulcer and gastric ulcer) [1], and the first description of duodenal ulcer in medical literature appeared in 1817 [2]. However, none of the theories has ever been able to elucidate the birth-cohort phenomenon [3,4], the morphology [5,6], the predilection sites [7], the relapse and multiplicity [8,9], the role of gastric acid in peptic ulcers [10,11], and many other characteristics and observations/phenomena of these two diseases [12]. The isolation of Helicobacter pylori (H. pylori) in 1982 was a revolutionary discovery to understand both diseases [13], and presently it is believed that there is a causal relationship between $H$. pylori and peptic ulcers [14], or even "No H. pylori, No Ulcer" [15]. Marshall et al. concluded that H. pylori was the most important etiological factor for duodenal ulcer in 1988 and they were awarded the Nobel Prize in Physiology or Medicine in 2005 for their discovery of this bacterium [14,16]. As a result, peptic ulcers are widely believed to be an infectious disease caused by the infection of $H$. pylori [9]. We designate this etiological theory as Theory of $H$. pylori. However, the role of $H$. pylori in peptic ulcers is controversial [17-21] and how the bacterial infection can lead to ulceration is presently unknown [16]. To date, no single theory can fully explain the pathogenesis of peptic ulcers. In fact, studies on other human diseases are very similar to peptic ulcers; no disease has ever been fully understood. For most of the characteristics and observations/phenomena of any disease, modern scientific reports usually use "remains unknown" or "needs more studies" to conclude their discussions.

In contrast, many more inspiring advancements have been made in Physics over the past 330 years. Since Isaac Newton published his Law of Universal Gravitational Force in 1687 [22], thousands of phenomena in physics were successfully explained. Albert Einstein attributed these great progresses to the first causal relationship established by Newton in the Law of Universal Gravitational Force (gravity causes objects to fall) [23], which is the hallmark of the birth of Macro-science. In 1905, Einstein published 3 articles on Theory of Relativity [24], Mass-energy Equation [25], and the Photoelectric Effect [26], respectively. These three articles discovered a second causal relationship in Physics (energy absorption causes electron transition) [27], which is the hallmark of the birth of Micro-science. These two historic causal relationships allowed major progress to be made in Physics [23].

The success in Physics indicates that establishing a causal relationship in Medicine may be the key to understanding human diseases [28]. Unfortunately, human diseases are much more complicated than the phenomena in Physics, leading to the failure of establishing a viable causal relationship in Medicine in the past three centuries. Fortunately, in May 2012, a book entitled Philosophical Principles of Life Science was published, proposing a new causal relationship for Medicine with its accompanying methodologies [29]. This new causal relationship can be explained by drawing a parallel to Newton's Law of Universal Gravitational Force or Einstein's Mass-energy Equation. In both causal relationships in Physics, Newton and Einstein took two essences of their research subjects into consideration: the visible, tangible and corporeal essence of MASS, which we define as Concrete Essence; and the invisible, intangible and incorporeal essence of FORCE or ENERGY, which we define as Abstract Essence. In Physics, the apple falls to 
the ground due to its Abstract Essence, FORCE, and electrons transition to new orbitals due to absorption of the Abstract Essence, ENERGY. Similarly, the recently established causal relationship in Medicine also suggests that the human body suffers from various diseases due to its invisible, intangible and incorporeal Abstract Essence, which has rarely been investigated in Modern Medicine.

Herein we systematically reviewed all the topics on peptic ulcers and applied the new causal relationship with its accompanying methodologies, epistemologies, and way of thinking to analyze the existing data. We found that the existing data accumulated during the past 300 years was in fact sufficient to fully understand this disease, but the significant basic theories and methodologies, which were essential to analyze the existing data, were not established until 2012. We summarized our review results into a series of seven articles to explain the pathogenesis of peptic ulcers, and this article is the second one of the series, exclusively focusing on the pathogenesis of duodenal ulcer. This systematic review aims to identify the cause of duodenal ulcer, address all the controversies surrounding $H$. pylori, elucidate the role of gastric acid, and describe the pathological process of duodenal ulceration.

\section{Methods}

\section{Search strategy and selection criteria}

This systematic review was done according to the PRISMA 2009 guidelines [30]. Eligible papers were published studies on numerous topics in the field of peptic ulcer research in the past 300 years. This included Genetics, Anatomy, Etiology, Psychology, Epidemiology, Neurology, Pathology, Bacteriology, Clinical Statistics, and pre-clinical studies. Our search terms included all known characteristics of peptic ulcers, such as $H$. pylori infection, gastric acid, epidemiology, morphology, relapse and multiplicity, and nonsteroidal anti-inflammatory drugs (NSAIDs). We also searched the reference lists of selected studies. However, the lab research, clinical observations, and epidemiological surveys of $H$. pylori infection after 2005 were excluded because of potential bias due to the impactful nature of the 2005 Nobel Prize in Physiology or Medicine [14]. Unreproducible studies were also excluded. If several studies had similar findings, we only selected the earliest paper because we determined the earliest papers provided the basis for the other similar studies that followed.

We searched Medline, Embase, Web of Science, and Google Scholar for articles before 2019 and databases were searched without language restrictions. We included studies from peer-reviewed journals including randomized trials, observational studies, original research articles (clinical and laboratory), reviews, commentaries, and editorials. For historical theories, we included proposed theories supported by multiple reproducible and randomized laboratory results, clinical observations or epidemiological surveys. Books published on peptic ulcers and on the pathogenesis of other human diseases were also included. Papers addressing characteristics or observations/phenomena of peptic ulcers were included. For the results from epidemiological surveys, different percentages for rates of $H$. pylori infection in peptic ulcer patients or in the population were also included. 


\section{Data extraction and quality assessment}

Studies that potentially met the inclusion criteria described above were selected. Two reviewers (S.X.M.D and K.J.R) assessed the abstracts and titles independently, and the full text of promising studies were retrieved. Two reviewers (S.X.M.D and K.J.R) independently evaluated the quality of the research and the risk of bias in selected studies by considering the following characteristics: peer reviewed, randomization, reproducibility, and multiplicity. Reviewed studies were grouped based on the characteristics of peptic ulcers, such as gastric acid, H. pylori, NSAIDs, etiology, and clinical treatments. For epidemiological survey inclusion, the studies needed to be conducted in different years, geographical areas, or countries. Any discrepancy between the two reviewers was resolved through discussion with a third reviewer (C.C.Y.C.).

\section{Data analysis}

Six steps were taken to analyze the existing data. First, reviewed data was summarized into several categories and then included studies were sub-categorized. Second, a recently published Causal Relationship for Medicine was used to identify the cause of peptic ulcers. Third, a novel concept, Integral Perspective, was applied to integrate historical theories to understand the pathological process of peptic ulceration, including the early, intermediate, and late phases. Fourth, a novel analytical method, Superposition Mechanism, was used to elucidate the roles of all the local aggressive factors in the duodenal bulbs. Fifth, results from the fourth step were applied to explain the observations/phenomena related to gastric acid, H. pylori, and NSAIDs. Lastly, all above results were summarized to illustrate the complete pathogenesis of duodenal ulcer, which could explain all the characteristics and observations/phenomena of this disease.

\section{Results}

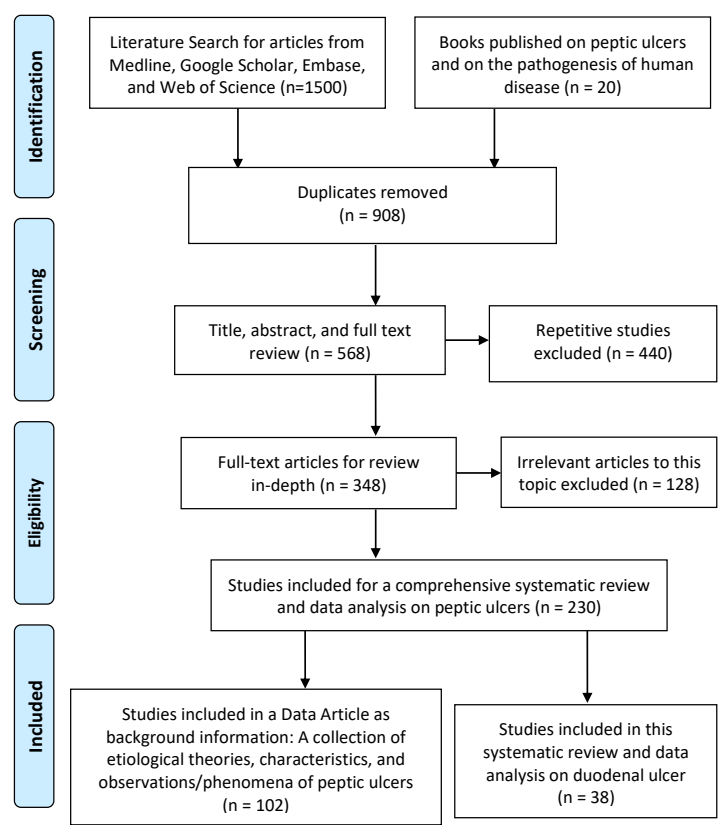

\section{Summarizing existing data}

A total of 1500 articles were selected for title review, 230 were eligible to review in-depth, and 38 were included for the systematic review and data analysis in this study (Figure 1). Reviewed data was summarized into three categories: etiological theories, characteristics, and observations/phenomena. Results of each category were sub-categorized based on selection criteria. The characteristics of included studies were shown (Table 1).

Figure 1: Preferred Reporting Items for Systematic Reviews and Meta-Analyses (PRISMA) flow diagram [30]. 
We found that there were 13 etiological theories in history attempting to elucidate the pathogenesis of peptic ulcers during the past 300 years, which included 15 characteristics and 81 observations/phenomena [31]; of all the 81 observations/phenomena, 36 were related to the infection of $H$. pylori [31]. Unfortunately, no single theory can explain all the 15 characteristics and 81 observations/phenomena of peptic ulcers [12]. In addition, of all the 36 observations/phenomena related to $H$. pylori, Theory of $H$. pylori could explain no more than 6 , and the roles of $H$. pylori and gastric acid in peptic ulcers have never been fully understood $[10,11]$.

\section{Table 1: Summary of characteristics of included studies}

\begin{tabular}{|c|c|c|c|c|c|}
\hline Category & $\begin{array}{c}\text { Selection } \\
\text { Criteria } \\
\end{array}$ & $\begin{array}{c}\text { Reviewed } \\
\text { in-depth }\end{array}$ & Results & $\begin{array}{c}\text { Sub-category of } \\
\text { Reviewed Studies }\end{array}$ & $\begin{array}{c}\text { Studies } \\
\text { Included }\end{array}$ \\
\hline \multirow[t]{2}{*}{$\begin{array}{l}\text { Etiological } \\
\text { Theories }\end{array}$} & \multirow[t]{2}{*}{$\begin{array}{l}\text { Supported by } \\
\text { multiple data; } \\
\text { duplicates are } \\
\text { excluded }\end{array}$} & \multirow[t]{2}{*}{19 studies } & \multirow[t]{2}{*}{$\begin{array}{l}13 \text { etiological } \\
\text { theories in history }\end{array}$} & $\begin{array}{l}11 \text { Supported by } \\
\text { multiple data }\end{array}$ & 11 \\
\hline & & & & 8 Un-supported & 0 \\
\hline \multirow{6}{*}{ Characteristics } & \multirow{6}{*}{$\begin{array}{l}\text { All Known } \\
\text { characteristics } \\
\text { in historical } \\
\text { studies; } \\
\text { duplicates are } \\
\text { excluded }\end{array}$} & \multirow{6}{*}{115 Studies } & \multirow{6}{*}{$\begin{array}{l}15 \text { major } \\
\text { characteristics }\end{array}$} & 17 Gastric acid & 7 \\
\hline & & & & 36 H. pylori & 11 \\
\hline & & & & 9 NSAIDs & 2 \\
\hline & & & & 14 Epidemiology & 4 \\
\hline & & & & $\begin{array}{l}24 \text { Clinical } \\
\text { Observations }\end{array}$ & 18 \\
\hline & & & & 15 Others & 6 \\
\hline \multirow{4}{*}{$\begin{array}{l}\text { Observations/ } \\
\text { Phenomena }\end{array}$} & \multirow{4}{*}{$\begin{array}{l}\text { Peer- } \\
\text { reviewed, } \\
\text { Reproducible, } \\
\text { randomized; } \\
\text { duplicates are } \\
\text { excluded }\end{array}$} & \multirow{4}{*}{96 studies } & \multirow{4}{*}{$\begin{array}{l}81 \text { major } \\
\text { observations/ } \\
\text { Phenomena; of } \\
\text { which } 36 \text { were } \\
\text { related to } H \text {. } \\
\text { pylori }\end{array}$} & 16 Duodenal Ulcer & 13 \\
\hline & & & & 16 Gastric Ulcer & 0 \\
\hline & & & & $\begin{array}{l}36 \text { Both Gastric } \\
\text { and Duodenal } \\
\text { Ulcer }\end{array}$ & 19 \\
\hline & & & & $36 \mathrm{H}$. pylori & 11 \\
\hline
\end{tabular}

\section{Identifying the cause of peptic ulcers}

Based on review results, we applied the causal relationship published in 2012 to identify the cause of peptic ulcers [29]. This new causal relationship dictates that "it is the invisible, intangible and incorporeal Abstract Essence of the human body that causes the occurrence of diseases". Out of all 13 historical theories, only Psychosomatics Theory (1950) $[32,33]$ and Stress Theory (1950) [34] suggest invisible, intangible and incorporeal causes for peptic ulcers (Table 2). In fact, the ideas of Psychosomatics Theory are similar to those of Stress Theory: Psychosomatics Theory focuses more on the impact of mental health related to past life experience, whereas Stress Theory focuses more on the influences of current life events. When combining the concepts from these two theories, we elucidated that psychosomatic factors made individuals more susceptible to psychological stress caused by current life events, leading to the eventual occurrence of peptic ulcers. A combination of the two historical theories indicates that peptic ulcers (including duodenal ulcer and gastric ulcer) are a psychosomatic disease triggered by psychological stress. 
Table 2: Five of 13 etiological theories in history were selected for detailed studies

\begin{tabular}{|c|c|c|c|}
\hline Etiological Theories & Founder \& Year & Repeat Example & Key Points \\
\hline $\begin{array}{l}\text { 1. No Acid, No Ulcer } \\
\text { [35] }\end{array}$ & $\begin{array}{l}\text { Dragutin (Carl) } \\
\text { Schwartz, } 1910\end{array}$ & P. Miner [36], 2004 & $\begin{array}{l}\text { Hypersecretion of gastric } \\
\text { acid is the cause of } \\
\text { peptic ulcers. }\end{array}$ \\
\hline 2. Nerve Theory [37] & $\begin{array}{l}\text { Von Bergmann } \\
\text { G., } 1913\end{array}$ & $\begin{array}{l}\text { G.B. Glavin, et al. } \\
{[38], 1991}\end{array}$ & $\begin{array}{l}\text { The abnormality of } \\
\text { neurotransmitters in the } \\
\text { central nervous system is } \\
\text { the cause of peptic } \\
\text { ulcers. }\end{array}$ \\
\hline $\begin{array}{l}\text { 3. Psychosomatics } \\
\text { Theory }[32,33]\end{array}$ & $\begin{array}{l}\text { Franz Gabriel } \\
\text { Alexander, } 1950\end{array}$ & $\begin{array}{l}\text { Mark Feldman, et al. [39], } \\
1986\end{array}$ & $\begin{array}{l}\text { Social, psychological, } \\
\text { and behavioral factors } \\
\text { are the cause of peptic } \\
\text { ulcers. }\end{array}$ \\
\hline 4. Stress Theory [34] & $\begin{array}{l}\text { Hans Selye, } \\
1950\end{array}$ & $\begin{array}{l}\text { Michael P. Jones [40], } \\
2006\end{array}$ & $\begin{array}{l}\text { Stress induced by } \\
\text { personality traits, and } \\
\text { social and natural events } \\
\text { is the cause of peptic } \\
\text { ulcers. }\end{array}$ \\
\hline $\begin{array}{l}\text { 5. Theory of H. Pylori } \\
\text { [16] }^{*}\end{array}$ & $\begin{array}{l}\text { Barry J. Marshal } \\
\text { and J. Robin } \\
\text { Warren, } 1988\end{array}$ & $\begin{array}{l}\text { T. Furuta, et al. [41], } \\
1998\end{array}$ & $\begin{array}{l}\text { Peptic ulcers are an } \\
\text { infectious disease } \\
\text { caused by the infection of } \\
\text { H. pylori. }\end{array}$ \\
\hline
\end{tabular}

Fortunately, many modern medical studies support that peptic ulcers are a psychosomatic disease triggered by psychological stress. This is also corroborated by clinical experiences of medical professionals and life experiences of the lay public [40]. Doll and Jones' survey suggested a positive correlation between stressful occupations and duodenal ulcer, and a decreased incidence of ulcer among agricultural workers due to the simplicity of their lives [42]. The birth-cohort phenomenon, first reported by Susser and Stein in 1962, indicated that there might be a causal relationship between stressful life events (World War I and The Great Depression) and peptic ulcers [3]. After summarizing their own clinical observations and previous studies, Peters and Richardson concluded that stressful events frequently preceded the onset of ulcer symptoms in both newly diagnosed and chronic ulcer patients [43]. Furthermore, Feldman's multidimensional case-controlled study indicated that ulcer patients exhibited significantly more emotional distress in the form of depression and anxiety [39].

Ford and Talley insisted that there is a causal relationship between H. pylori and duodenal ulcer [17], but Hobsley et al. believed that gastric acid secretion plays more important roles than H. pylori infection in this disease [18]. However, neither H. pylori nor gastric acid is invisible, intangible and incorporeal; therefore, both factors do not match the standard set by the new causal relationship to be the cause of disease. Conceivably, the etiology based on either $H$. pylori or gastric acid could not explain the pathogenesis of peptic ulcers, even though both were supported by multiple laboratory results, clinical observations, and epidemiological surveys. In fact, the hyper-secretion of gastric acid can be an effect caused by psychological stress as observed in clinical patients [43,44]. Additionally, results from epidemiological surveys and clinical observations found that there were many H. pylori negative patients [21,45], further indicating that $H$. pylori infection was not the cause of duodenal ulcer. 


\section{Integrating etiological theories in history}

After the etiology was identified, we examined the 13 historical theories in more detail. Although none of them could fully explain the pathogenesis of peptic ulcers, they were supported by valid laboratory results, clinical observations or epidemiological surveys, and did make important discoveries for this disease. We also found that each historical theory focused on only one area of the human body. For example, Nerve Theory only focused on the abnormal neurotransmitters in the brain [38], No Acid, No Ulcer was solely concerned with the hypersecretion of gastric acid in the stomach [35], and Marshall et al. concentrated exclusively on Bacteriology in the upper digestive tract [16].

The causal relationship published in 2012 dictates that all different parts of the human body are universally correlated to each other by its Abstract Essence [29]. Accordingly, looking at the human body as an integrated whole, and not just pieces, may allow us to gain unprecedented insights into human disease. Therefore, integrating historical theories on peptic ulcers into one single theory may provide us a holistic view of this disease. We found that an integration of five historical theories (Table 2) did in fact paint a complete picture of the pathogenesis of peptic ulcers, including the early, intermediate, and late phases of peptic ulceration. The early phase is characterized by the triggering of psychological stress as indicated in Psychosomatics Theory and Stress Theory [33,34]. Nerve Theory describes the intermediate phase of peptic ulcers, which uncovers the consequence of psychological stress, suggesting that peptic ulcers are brain-driven events resulting in the transmission of aberrant nerve impulses to the stomach [38]. The late phase of peptic ulceration is characterized by the damage from aggressive factors in the stomach and is described by No Acid, No Ulcer and Theory of H. pylori $[16,35]$.

\section{Superposing all the local aggressive factors in the stomach}

Our literature reviews indicate that most of current controversies on peptic ulcers concentrated on the late phase of ulceration, especially on the roles of $H$. pylori and gastric acid. Thus, to further understand the late phase of duodenal ulceration, we analyzed the existing data for all known local aggressive factors in the stomach, including gastric acid, $H$. pylori, mechanical abrasion, and medications such as NSAIDs $[9,46,47]$. We found that the local aggressive factors were studied as separate entities in Modern Medicine, and they had never been considered as a combinatorial force to corrupt the mucosa. However, the concept of Integration, originating from the new causal relationship, indicates that a pathological process is caused not by an individual aggressive factor, but by many factors based on Superposition Mechanism [29]. Graham and Yamaoka's results indicate that the hypersecretion of gastric acid is a determinant factor in the final stage of duodenal ulceration [18,48], but the other aggressive factors in the stomach also contribute to the corrosive intensity [46], ultimately resulting in duodenal ulceration when the total corrosive intensity exceeds the resistance of the mucosa of duodenal bulbs. Therefore, it is the total sum of corrosive intensities from all local aggressive factors acting on the duodenal bulb that leads to the characteristic erosive appearance of the duodenal ulcer. Based on these analyses, we summarized all the clinical and epidemiological data we reviewed into 21 cases (Figure 2). 


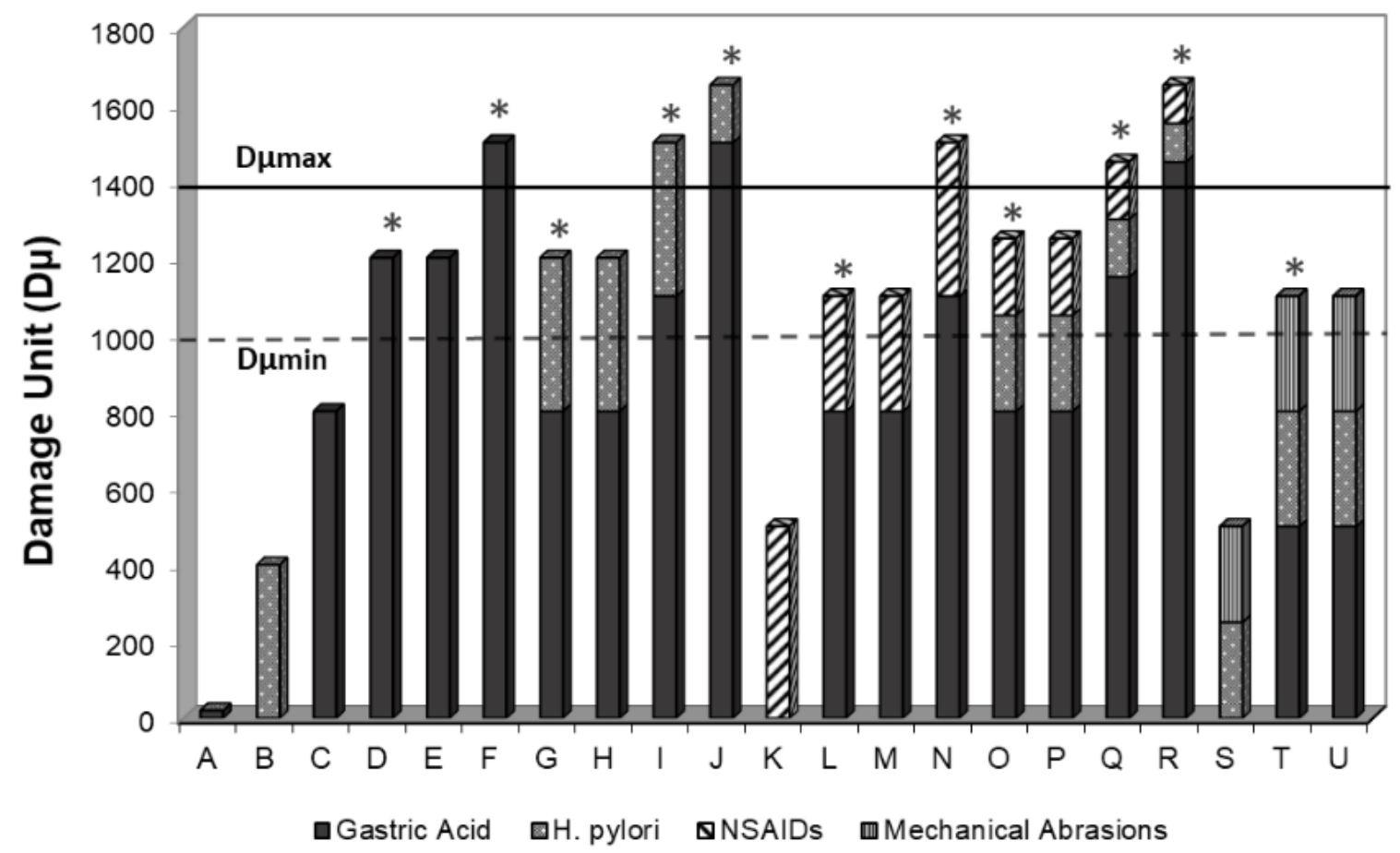

Figure 2. The Superposition Mechanism of local aggressive factors in duodenal ulceration

The hypersecretion of gastric acid is a determinant factor in final duodenal ulceration, but all other local aggressive factors are also involved. We define the corrosive intensity caused by an aggressive factor as Damage Unit $(\mathrm{D} \mu)$, and the total sum of corrosive intensities of each case $(\Sigma \mathrm{D} \mu)$ is calculated individually by the formula: $\Sigma \mathrm{D} \mu=\mathrm{D} \mu_{\text {Gastric Acid }}$ $+\mathrm{D} \mu_{\text {H. pylori }}+\mathrm{D} \mu_{\mathrm{NSAIDs}}+\mathrm{D} \mu_{\text {Mechanical Abrasions. }}$. Due to distinct genetic backgrounds and life experiences, the susceptibility of duodenal mucosa varies from person to person. Accordingly, each individual has her/his own threshold of ulceration. Therefore, we set a theoretical range between $D \mu_{\min }$ and $D \mu_{\max }$ as the threshold of ulceration. $\Sigma D \mu$ values per individual case below $\mathrm{D} \mu_{\min }$ (dash line) will not result in ulceration, $\Sigma \mathrm{D} \mu$ values above $\mathrm{D} \mu_{\max }$ (solid line) will result in ulceration, and $\Sigma \mathrm{D} \mu$ values within the range may or may not result in ulceration. When the $\Sigma \mathrm{D} \mu$ value falls between $\mathrm{D} \mu_{\min }$ and $D \mu_{\max }$, even though some individuals have the same $\Sigma \mathrm{D} \mu$ value, the one whose duodenal mucosa is more susceptible to the local aggressive factors are more likely to ulcerate. * indicates cases of ulceration.

In Figure 2, Case A demonstrates an $\mathrm{H}$. pylori-negative individual who has normosecretion and suffers no damage $(D \mu=0)$. This is the baseline for normal, healthy individuals. Case B represents the most common situation for individuals with normosecretion and $H$. pylori infection. Although they suffer some damage from the H. pylori infection, the $\Sigma D \mu$ value does not reach the lowest threshold, $D \mu$ min, meaning the individuals do not suffer from ulceration. Cases C, D, E and $\mathrm{F}$ are H. pylori-negative examples where different degrees of hypersecretion determine the $\Sigma D \mu$ value. Case $C$ does not ulcerate $\left(\Sigma D \mu_{c}<D \mu_{\min }\right)$, Case $D$ ulcerates because $D \mu_{\min }<\Sigma D \mu_{D}<D \mu_{\max }$ and Case $F$ has high-range hypersecretion $\left(\Sigma D \mu_{F}>D \mu_{\max }\right)$, which results in ulceration. Although Case $E$ has the same $\Sigma D \mu$ as Case $D\left(\Sigma D \mu_{E}=\Sigma D \mu_{D}\right)$, Case $E$ does not ulcerate because her/his gastric mucosa is less susceptible than Case $D$. 
Case $\mathrm{G}$ and Case $\mathrm{H}$ give examples of patients with similar $\Sigma \mathrm{D} \mu$ values due to corrosive intensity from superposition of both low-range hypersecretion of gastric acid and $\mathrm{H}$. pylori infection. Both cases are within the range for potential ulceration, however, the individuals in Case $\mathrm{G}$ vs. Case $\mathrm{H}$ have different mucosal susceptibility; therefore, Case $\mathrm{G}$ progresses to ulceration whereas Case $\mathrm{H}$ does not. Case I represents the $\Sigma \mathrm{D} \mu$ value for H. pyloripositive patients with mid-range hypersecretion. Although the corrosive intensity of acid alone does not overcome the individual's mucosal resistance to ulceration, with the addition of the damage from $H$. pylori the $\Sigma D \mu$ value surpasses $D \mu \max$ and the patient suffers ulceration. Case $\mathrm{J}$ is an example of an $H$. pylori-positive patient with high-range hypersecretion. With or without the damage from H. pylori, the hypersecretion exceeds $D \mu_{\max }$, resulting in ulceration.

Case $\mathrm{K}$ illustrates normo-secretion with NSAIDs use, wherein the $\Sigma D \mu$ value does not reach $D \mu$ min. The damage from the NSAIDs alone is not enough to cause ulceration. Cases $L$ and $M$ represent the additive damage of low-range hypersecretion and NSAIDs usage. In both cases, the damage from the gastric acid alone does not reach $D \mu$ min, but with the addition of the corrosive intensity from NSAIDs, the $\Sigma D \mu$ enters the threshold for potential ulceration. However, only Case $L$ ulcerates because her/his duodenal mucosa is more susceptible to local aggressive factors than Case $\mathrm{M}$. Case $\mathrm{N}$ is an example of the additive damage of mid-range hypersecretion and NSAIDs usage, but in this case, the patient ulcerates because $D \mu$ Gastric Acid $+D \mu N S A I D s>D \mu \max$.

Cases $\mathrm{O}$ and $\mathrm{P}$ illustrate $H$. pylori-positive individuals with low-range hypersecretion and NSAIDs usage, wherein $D \mu_{\min }<\Sigma D \mu<D \mu_{\max }$. However, only Case O ulcerates because this individual is more susceptible than Case P. When H. pylori-positive individuals use NSAIDs, the damage caused by either factor is slightly offset [49]. Case $Q$ represents the $\Sigma \mathrm{D} \mu$ value for $H$. pylori positive, NSAIDs using patients with mid-range hypersecretion. Although the corrosive intensity of the hypersecretion of gastric acid alone is less than $D \mu_{\max }$, the addition of the damage from H. pylori and NSAIDs causes the $\Sigma D \mu$ value to surpass $D \mu$ max and the patient suffers ulceration. Case $R$ represents the $\Sigma D \mu$ value from high-range hypersecretion, $H$. pylori infection, and NSAIDs usage, wherein the corrosive intensity of the acid alone surpasses $D \mu_{\max }$ and causes ulceration. In this case, the $D \mu$ values from $H$. pylori and NSAIDs do not significantly contribute to the ulceration process. Case $\mathrm{S}$ illustrates normo-secretion with $H$. pylori infection and NSAIDs use, wherein the $\Sigma D \mu$ value does not reach $D \mu$ min. The damage from the $H$. pylori and NSAIDs is not enough to cause ulceration. Cases $T$ and $U$ show similar situations with low-range hypersecretion, $H$. pylori infection, and corrosive medication. In these cases, the use of corrosive medications, such as chemotherapy drugs, exert damage on the duodenal bulb causing the $\Sigma D \mu$ value to enter the ulceration threshold. Case T ulcerates, but Case $U$ does not due to different susceptibility.

In summary, cases $A, B, C, K$, and $S$ have $\Sigma D \mu$ values that are less than $D \mu \min$ and do not result in ulceration. Cases $F, I, J, N, Q$, and $R$ are clinical duodenal ulcer patients because their $\Sigma D \mu$ values surpass $D \mu_{\max }$. Cases $D, G, L, O$, and Thave $\Sigma D \mu$ values within the threshold range for ulceration and they ulcerate due to their susceptibility to local aggressive factors. Cases $\mathrm{E}, \mathrm{H}, \mathrm{M}, \mathrm{P}$, and $\mathrm{U}$ also have $\Sigma \mathrm{D} \mu$ values within the threshold range for ulceration, but they do not ulcerate because the corrosive intensity cannot overcome their individual resistance to local aggressive factors. 


\section{Elucidating the roles of $\boldsymbol{H}$. pylori and gastric acid}

Figure 2 can help to understand all the observations/phenomena related to gastric acid, $\mathrm{H}$. pylori infection, NSAIDs, and other medications in duodenal ulcer. Since each of the local aggressive factors partially contributes to the corrosive intensity, and duodenal ulceration is caused by the total corrosive intensity; the higher the density of $\mathrm{H}$. pylori, the higher total corrosive intensity, causing a higher clinical morbidity. Therefore, Cases B to $\mathrm{J}$ explain that $H$. pylori density is related to the morbidity of duodenal ulcers [49] and Cases $\mathrm{K}$ to $\mathrm{R}$ explain that duodenal ulcers in $\mathrm{H}$. pylori-negative patients are presumably due to NSAIDs [50]. Without the hypersecretion of gastric acid, the corrosive intensity caused by $H$. pylori itself could not reach the threshold of ulceration. Therefore, Graham and Yamaoka concluded that $\mathrm{H}$. pylori-positive patients require the hypersecretion of gastric acid to progress to duodenal ulcer [48], indicating H. pylori infection is not the most important etiological factor of duodenal ulcer [16], but second to the hypersecretion of gastric acid. Similar to gastric acid secretion, $H$. pylori infection is not the cause of duodenal ulcer but plays a secondary role in only the late phase of duodenal ulceration, exacerbating clinical symptoms and increasing the clinical morbidity/mortality of this disease.

Case B is applicable to most $H$. pylori-infected individuals, as Elitsur and Lawrence's survey found that "in spite of a high prevalence of $H$. pylori infection worldwide, the incidence of duodenal ulcer disease is low" [45]. Comparing Cases C and G demonstrate Roma's finding that the morbidity of duodenal ulcer is increased in $H$. pylori infected individuals [51]. Contrasting Cases $D$ and $G$ or $F$ and I illustrate the conclusion from a study in northern Italy and Denmark that " $H$. pylori-negative duodenal ulcers were associated with a poorer prognosis mainly because of a higher rate of ulcer and symptom relapse" [9]. In order to reach ulceration without the corrosive intensity from $\mathrm{H}$. pylori, the hypersecretion of gastric acid needs to be higher in H. pylori-negative patients. The higher hypersecretion in Cases $D$ and $F$ indicates more severe negative impacts from psychosocial stress than in Cases $\mathrm{G}$ and I. Additionally, the damage from H. pylori can be relieved by antibiotics, as in Cases $\mathrm{G}$ and I, decreasing the corrosive intensity in these patients; whereas Cases $D$ and $F$ cannot achieve the same therapeutic effect. Therefore, there is a poorer prognosis and a higher relapse rate in $H$. pylori-negative patients $[9,52,53]$. Moreover, Figure 2 indicates that the classification of duodenal ulcer into three categories (H. pylori-related, NSAIDs-related, and non- H. pylori/non-NSAIDs-related [54]) overlooks the determinant factor in the occurrence of duodenal ulcer, the hypersecretion of gastric acid.

Figure 2 further identified that gastric acid is the most important local aggressive factor in the late phase of duodenal ulcer [48] and that $H$. Pylori is a secondary contributor to the process, as indicated by Cases $\mathrm{D}, \mathrm{F}, \mathrm{L}$, and $\mathrm{N}$ where ulceration is reached without H. pylori. These four cases support the finding that in some countries, $30-40 \%$ of duodenal ulcer patients are $H$. pylori-negative [21]. In addition, these cases also help to explain the high relapse rate of duodenal ulcer (up to $20 \%$ ) despite treating all patients with antibiotics targeting $H$. pylori [55]. Cases $\mathrm{J}$ and $\mathrm{R}$ explain that many duodenal ulcers are falsely attributed to $H$. pylori infection because the majority of the damage in these cases comes from the hypersecretion of gastric acid [55]. Furthermore, Case J exemplifies Laine's findings that etiological factors other than $H$. pylori play a significant role in duodenal ulcer 
because there is a $20 \%$ relapse rate within six months despite successful eradication of H. pylori [56].

\section{Painting a complete picture of the pathogenesis of duodenal ulcer}

The data analysis above indicates that an integration of five historical theories, Psychosomatics Theory, Stress Theory, Nerve Theory, "No Acid, No Ulcer", and Theory of H. pylori, can paint a complete picture of the pathogenesis of duodenal ulcer, including the early, intermediate, and late phases of the ulceration process. Each phase of this process is supported by a large amount of existing data and dividing the ulceration process into three phases can help us to fully understand many characteristics and observations/ phenomena of duodenal ulcer, which have never been elucidated before.

\section{Early phase: psychological stress}

In the early phase of duodenal ulcer, psychosomatic factors such as hypochondriasis, a negative perception of life events, dependency, and lowered self-confidence, made ulcer patients more susceptible to stress than controls [39]. Levenstein and colleagues found that of 33 patients with active ulcer, the symptoms of 16 patients had been preceded by severe stress and more pathological results from the Minnesota Multiphasic Personality Inventory [57]. The clinical observations from Peters et al and Levenstein et al indicated that symptomatic exacerbations of peptic ulcer disease occurred during or shortly after stressful events $[43,57]$. Both studies suggested that perception of stress was the early phase of the disease. Doll and Jones' survey discovered a positive correlation between stressful occupations and duodenal ulcer [42]. A perspective study indicated duodenal ulcer was usually related to bad habits, poor life style, laborious work, unhealthy environment and/or long-term emotional distress [58]. All these observations indicate that the early phase of duodenal ulcer is usually long-term and chronic [59]. The long-term and chronic stress of the human condition cannot be simulated in labs; accordingly, animal models for duodenal ulcer are difficult to establish [38].

\section{Intermediate phase: hypersecretion of gastric acid}

Psychosomatic stress induced in the early phase causes abnormal release of neurotransmitters in the Central Nervous System (CNS), leading to the transmission of pathogenic nerve impulses to the stomach. Thus, duodenal ulcer is a brain-driven event accompanied by psychological symptoms such as insomnia, anxiety, and anorexia [60]. Joëls' analysis (2004) suggested that duodenal ulcer is a brain-driven event related to the activation of the hypothalamus-pituitaryadrenal axis (HPA), resulting in the release of corticosteroid hormones [61]. The long term and chronic pathogenic nerve impulses may lead to the hyperplasia and hypertrophy of local gastric glands [61,62]. Subsequently, the individuals become more sensitive to stress induced by life events, causing the abnormal hypersecretion of gastric acid. Many studies have demonstrated that duodenal ulcer patients have higher basal and maximal gastric acid secretion as well as pepsin output $[36,63]$. 


\section{Late phase: symptomatic duodenal ulcer}

The late phase of duodenal ulcer is a corrosive process caused by local aggressive factors, including gastric acid and pepsin, H. pylori, mechanical abrasion, and chemical erosion from medications such as NSAIDs. Kirsner and Palmer believed that peptic ulceration was not an infectious process, but a corrosive one [64]. Notably, the hypersecretion of gastric acid is unrelated to the local aggressive factors in the gastrointestinal tract, such as $H$. pylori infection and mechanical abrasion, but is caused by pathogenic nerve impulses from the CNS [38]. Moreover, the hypersecretion of gastric acid is a determinant factor in the late phase of duodenal ulceration and governs many characteristics of this disease, especially the observations related to H. pylori [48]. Miner's review found that duodenal ulcer patients have pain relief when the gastric acid is buffered or neutralized with alkali or food, demonstrating the importance of gastric acid in this disease [36]. However, the hypersecretion of gastric acid is not the cause of duodenal ulcer as proposed by Dragutin (Carl) Schwartz in his dictum "No Acid, No Ulcer" [35], but an effect of pathogenic nerve impulses from the CNS due to psychological stress caused by personality traits and/or life events.

\section{Discussion}

Approximately 13 theories have been proposed to elucidate the pathogenesis of peptic ulcers in history [31], but none of them could fully explain this disease [12]. Currently, the infection of $\mathrm{H}$. pylori is widely believed to be the cause of duodenal ulcer in Modern Medicine [9], but the role of this bacterium remains unknown and the etiology based on this bacterium could not explain the pathogenesis of this disease [16]. Herein we applied a new causal relationship with its accompanying methodologies to identify the cause of peptic ulcers (including duodenal ulcer and gastric ulcer), and to analyze the existing data. Encouragingly, together with our five other papers, we could fully explain all the 15 characteristics and 81 observations/phenomena of peptic ulcers, including all the 36 observations/phenomena related to $H$. pylori. Our series of papers leaves no characteristics and observations/phenomena of peptic ulcers unexplained.

Interestingly, our explanation described herein indicates that the individual theories proposed in history, such as Psychosomatics Theory, Stress Theory, Nerve Theory, "No Acid, No Ulcer", and Theory of H. pylori, can be combined together to achieve a complete explanation of the pathogenesis of duodenal ulcer. Duodenal ulceration is initiated by psychological stress as described in Psychosomatics Theory and Stress Theory, resulting in abnormal neurotransmitters in the CNS as discovered by Nerve Theory. The subsequent pathogenic nerve impulses cause the hypersecretion of gastric acid; "No Acid, No Ulcer" and Theory of H. pylori studied the erosive process in the late phase of duodenal ulceration. Thus, once combined, the historical theories originating from Modern Medicine, were in fact sufficient to paint a complete picture to describe the pathogenesis of duodenal ulcer.

To take it one step further, we investigated the basic methodology of Modern Science to determine why modern medical research is conducted in an isolated fashion. We found 
that it was Reductionism that prohibited merging the existing data to explain the pathogenesis of duodenal ulcer. Originated from Rene Decartes (1596-1650), Reductionism states that a system is nothing but a sum of its own parts [65]. Thus, it attempts to explain an entire system in terms of its individual parts. This concept formed the methodological basis of Modern Science, which featured the division of research fields. As a result, Modern Science was divided into several main branches such as Life Science, Physical Science, Medical Science and Social Science. Each main branch was further divided into thousands of sub-branches; in the case of Life Science this includes Biology, Cell Biology, Molecular Biology, etc. Similarly, the research on the human body was also divided into a descending structural hierarchy: systems, organs, tissues, cells, organelles, and biological molecules. Moreover, a modern hospital is split into many divisions and sub-divisions, each focusing on only one system or organ. In the case of peptic ulcers, psychologists concentrated their attention only on life events and proposed Psychosomatics Theory and Stress Theory to explain the pathogenesis of this disease. Neurologists focused only on the neurotransmitters in the CNS and propositioned Nerve Theory, whereas gastroenterologists emphasized the importance of hypersecretion of gastric acid and suggested "No Acid, No Ulcer" in clinical cases. Finally, bacteriologists sought only a bacterial etiology and proposed $H$. pylori to be the cause of this disease. Governed by the rules of Reductionism, modern medical research excludes other areas of study from their scope, making it impossible to put these individual theories together to form an integrated view of the pathogenesis of duodenal ulcer.

The methodologies derived from Reductionism may lead to important correlations and amalgamating factors going unnoticed. For example, Isaac Newton regarded the apple and the Earth as an integrated, inseparable system when he was explaining the apple falling to the ground. If he considered this system as nothing but a sum of the apple and the Earth as Reductionism states, then gravity, which is an invisible abstract correlation between the apple and the Earth, would have been overlooked. Consequently, why the apple always falls to the ground would have never been explained. Newton's success indicated that a system could not simply be regarded as a sum of its parts and that there was an invisible, intangible, incorporeal driving force playing an essential role within the system. Evidently, many features of a system can go unnoticed when using the methodologies derived from Reductionism, but these overlooked features play crucial roles to drive the changes and developments of the system.

Similarly, modern medical methodologies derived from Reductionism may also overlook many integral features of the human body, which are essential to understand various life phenomena and human diseases. Our explanation of the pathogenesis of duodenal ulcer indicates that the overlooked features are the non-structural parts of the human body, which are invisible, intangible and incorporeal. Accordingly, we termed these features the Abstract Essence of the human body. The Abstract Essence, such as intelligence, memory, life-view, emotion, and various social relationships, may play the same role as gravity in the apple falling to the ground. Thus, the Abstract Essence might be the real cause of various human diseases but is rarely included in the scope of modern medical research due to a commitment to Reductionism. Consequently, the real causes of various life phenomena or human diseases are excluded from the scope of studies before modern medical research starts. For example, despite the fact that it is well known in Modern 
Medicine that the secretion of gastric acid is controlled by the CNS, there was still an assumption that " $H$. pylori infection affects gastric acid secretion" [41], indicating modern medical research overlooked the correlation between the CNS and the stomach. Consequently, the true cause of duodenal ulcer remained elusive.

The causal relationship published in 2012 indicates that all individual parts of the human body are universally correlated to each other by the Abstract Essence of the human body. Therefore, a novel methodological concept termed Integral Perspective, was derived to direct our data analysis [29]. This concept dictates that the human body is an integrated, inseparable system, guiding us to combine all historical theories together, to completely illustrate the pathogenesis of duodenal ulcer. Moreover, this new concept also indicated that all local aggressive factors in the stomach should be taken into consideration. Thus, Superposition Mechanism was derived to understand and calculate the additive effects of multiple factors simultaneously influencing duodenal ulcer progression. As a result, Figure 2 was deduced to fully understand the late phase of duodenal ulceration. Therefore, once the concepts of Integral Perspective and Superposition Mechanism are put into practice, a complete picture including all the phases of duodenal ulceration can be painted to fully understand the pathogenesis of duodenal ulcer.

Most importantly, Integral Perspective is the key concept to understand the roles of $H$. pylori and gastric acid in duodenal ulcer. Not until a complete picture of the pathogenesis of duodenal ulcer was painted and the local aggressive factors were all taken into consideration, could we elucidate the roles of $\mathrm{H}$. pylori and gastric acid in duodenal ulcer. Unequivocally, only the factors in the early phase can be identified as the cause of a disease. However, the early phase of duodenal ulceration is unrelated to both gastric acid and $\mathrm{H}$. pylori, indicating that this disease is not triggered by either factor. Moreover, the 21 cases in Figure 2 indicate that the phenomena in Medicine are much more complex than those in Physics; therefore, we should not attribute the cause of life phenomena or human diseases to only one factor, such as the infection of $H$. pylori or the hypersecretion of gastric acid $[17,18]$.

In summary, our study indicated that the existing data is sufficient to fully understand the pathogenesis of duodenal ulcer. However, modern medical research breaks down the human body into minute pieces and studies each piece separately. This methodology overlooks the invisible, intangible, and incorporeal Abstract Essence of the human body, which might be the real cause of various diseases. The application of a new causal relationship identified the cause of duodenal ulcer. Its accompanying methodology, Integral Perspective, directed us to combine five historical theories together, as well as all the local aggressive factors in the stomach, to fully understand the pathogenesis of duodenal ulcer. A second concept, Superposition Mechanism, allowed us to analyze and understand the data and literature we reviewed. Our results indicate that duodenal ulcer is not an infectious disease caused by the infection of Helicobacter pylori, but a psychosomatic disease triggered by psychological stress. Neither H. pylori nor gastric acid is the cause of duodenal ulcer. Nevertheless, both of them play a role in only the late phase of this disease, exacerbating clinical symptoms and increasing clinical morbidity/mortality. 


\section{Author Contribution}

S.X.M.D. designed the study, searched and reviewed papers, applied the new basic theory and methodologies to analyze the existing data and drafted the manuscript. K.J.R. reviewed papers, drafted some paragraphs, challenged the ideas and intellectually contributed to editing and revising the manuscript. C.C.Y.C. reviewed papers, summarized and interpreted the analyses into figures. All three authors critically reviewed the manuscript.

\section{Acknowledgements}

We would like to extend our special thanks to Alison Cheung, Douglas Rowe and Jonathan Weldrick for their useful comments and helpful draft revisions.

\section{Funding statement}

This research received no specific grant from any funding agency in the public, commercial or not-for-profit sectors.

\section{Declarations of competing interests}

The authors have no competing interests to report.

\section{References}

[1] M. Kidd, I.M. Modlin, A Century of Helicobacter pylori, Digestion. 59 (1998) 1-15. doi:10.1159/000007461.

[2] R.S. Boles, Modern Medical and Surgical Treatment of Peptic Ulcer: An Appraisal, J. Am. Med. Assoc. 136 (1948) 528-535. doi:10.1001/jama.1948.02890250016004.

[3] M. Susser, Z. Stein, Civilisation and peptic ulcer, Lancet (London, England). 1 (1962) 115-9. http://www.ncbi.nlm.nih.gov/pubmed/13918500.

[4] A. Sonnenberg, H. Müller, F. Pace, Birth-cohort analysis of peptic ulcer mortality in Europe, J. Chronic Dis. 38 (1985) 309-317. doi:10.1016/0021-9681(85)90077-3.

[5] A. Damon, A.P. Polednak, Constitution, genetics, and body form in peptic ulcer: a review, J. Chronic Dis. 20 (1967) 787-802.

[6] J. Carton, R. Daly, P. Ramani, Clinical Pathology, Oxford University Press, 2007.

[7] P. Malfertheiner, F.K.L. Chan, K.E.L. McColl, Peptic ulcer disease, Lancet. 374 (2009) 1449-1461. doi:10.1016/S0140-6736(09)60938-7.

[8] J. Parsonnet, Helicobacter pylori: the size of the problem, Gut. 43 Suppl 1 (1998) S6-9. http://www.ncbi.nlm.nih.gov/pubmed/9764031.

[9] C. Quan, N.J. Talley, Clinical reviews: Management of peptic ulcer disease not related to Helicobacter pylori or NSAIDs, Am. J. Gastroenterol. 97 (2002) 2950. http://dx.doi.org/10.1111/j.1572-0241.2002.07068.x.

[10] M.E.V.A.N. Leerdam, G.N.J. Tytgat, Review article : Helicobacter pylori infection in peptic ulcer haemorrhage, 16 (2002) 66-78.

[11] U. States, How does Helico bacter pylori cause duodenal ulcer disease: The bug, the host , or both ?, (2002) 8-12.

[12] H. Kuang, Peptic Ulcer Diseases, People's Medical Publishing House, Beijing, 1990.

[13] C. Ciacci, G. Mazzacca, The history of Helicobacter pylori: A reflection on the relationship 
between the medical community and industry, Dig. Liver Dis. 38 (2006) 778-780. doi:10.1016/j.dld.2006.06.013.

[14] R. Zetterström, The Nobel Prize in 2005 for the discovery of Helicobacter pylori: Implications for child health, Acta Paediatr. Int. J. Paediatr. 95 (2006) 3-5. doi:10.1080/08035250500479616.

[15] D.Y. Graham, Campylobacter pylori and peptic ulcer disease, Gastroenterology. 96 (1989) 615-625. http://www.ncbi.nlm.nih.gov/pubmed/2642447.

[16] B.J. Marshall, C.S. Goodwin, J.R. Warren, R. Murray, E.D. Blincow, S.J. Blackbourn, M. Phillips, T.E. Waters, C.R. Sanderson, Prospective double-blind trial of duodenal ulcer relapse after eradication of Campylobacter pylori., Lancet (London, England). 2 (1988) 1437-42. doi:10.1016/s0140-6736(88)90929-4.

[17] A.C. Ford, N.J. Talley, Head to Head: Does Helicobacter pylori really cause duodenal ulcers? Yes, BMJ. 339 (2009) b2784-b2784. doi:10.1136/bmj.b2784.

[18] M. Hobsley, F.I. Tovey, K.D. Bardhan, J. Holton, Head to Head: Does Helicobacter pylori really cause duodenal ulcers? No, BMJ. 339 (2009) b2788-b2788. doi:10.1136/bmj.b2788.

[19] C.O. Record, P.C. Rubin, Controversies in management: Helicobacter pylori is not the causative agent, BMJ. 309 (1994) 1571-1572. https://www.bmj.com/content/309/6968/1571.

[20] V. Kate, N. Ananthakrishnan, F.I. Tovey, Is Helicobacter pylori Infection the Primary Cause of Duodenal Ulceration or a Secondary Factor? A Review of the Evidence, Gastroenterol. Res. Pract. 2013 (2013) 1-8. doi:10.1155/2013/425840.

[21] F.I. Tovey, M. Hobsley, Review: is Helicobacter pylori the primary cause of duodenal ulceration?, J. Gastroenterol. Hepatol. 14 (1999) 1053-1056. doi:10.1046/j.14401746.1999.02005.x.

[22] I. Newton, A.E. Shapiro, The Principia: Mathematical Principles of Natural Philosophy, Phys. Today. (2000). doi:10.1063/1.883005.

[23] P. Forman, Einstein and Newton: Two Legacies, Wilson Q. 3 (1976) 107-114. https://www.jstor.org/stable/40255566.

[24] A. Einstein, On the Electrodynamics of Moving Bodies, Ann. Phys. 17 (1905) 891-921. doi:10.1016/B978-0-08-006995-1.50014-4.

[25] A. Einstein, Ist die Trägheit eines Körpers von seinem Energieinhalt abhängig?, Ann. Phys. 323 (1905) 639-641. doi:10.1002/andp.19053231314.

[26] A. Einstein, Concerning an Heuristic Point of View Toward the Emission and Transformation of Light, Ann. Phys. 17 (1905) 132-148. doi:10.1119/1.1971542.

[27] F. Weinert, Einstein, Science and Philosophy, Philos. Sci. (2009) 99-133. doi:10.4000/philosophiascientiae.305.

[28] A.V. Carneiro, Causal relationships in medicine., Rev. Port. Cardiol. 24 (2005) 443-449. http://www.ncbi.nlm.nih.gov/pubmed/15929627.

[29] S.X.M. Dong, C.C.Y. Chang, Philosophical Principles of Life Science, Wunan Culture Enterprise, Taipei, 2012.

[30] D. Moher, A. Liberati, J. Tetzlaft, D.G. Altman, Preferred reporting items for systematic reviews and meta analysis: The PRISMA statement., BMJ. 3 (2009) 123-130. doi:10.1371/journal.pmed1000097.

[31] S.X.M. Dong, C.C.Y. Chang, K.J. Rowe, A collection of the etiological theories, characteristics, and observations/phenomena of peptic ulcers in existing data, Data $\mathrm{Br}$. 19 (2018) 1058-1067. doi:10.1016/j.dib.2018.05.022.

[32] H.M. Wolowitz, Oral involvement in peptic ulcer, J. Consult. Psychol. 31 (1967) 418-419. doi:10.1037/h0024861.

[33] F. Alexander, Fundamental Concepts of Psychosomatic Research: Psychogenesis, Conversion, Specificity, Psychosom. Med. 5 (1943) 205. doi:10.1097/00006842- 
194307000-00001.

[34] H. Selye, The physiology and pathology of exposure to stress, Acta, Oxford, England, 1950.

[35] S. Fatović-Ferenčić, M. Banić, No acid, no ulcer: Dragutin (Carl) Schwarz (1868-1917), the man ahead of his time, Dig. Dis. 29 (2011) 507-10. doi:10.1159/000334384.

[36] P. Miner, Review article: Relief of symptoms in gastric acid-related diseases - Correlation with acid suppression in rabeprazole treatment, Aliment. Pharmacol. Ther. 20S6 (2004) 20-29. doi:APT2162 [pii] \r10.1111/j.1365-2036.2004.02162.x.

[37] G. von Bergmann, Ulcus duodeni und vegetatives nerve system, Berl Klin Wchnscher. 50 (1913) 2374.

[38] G.B. Glavin, R. Murison, J.B. Overmier, W.P. Pare, H.K. Bakke, R.G. Henke, D.E. Hernandez, The neurobiology of stress ulcers, Brain Res. Rev. 16 (1991) 301-343. doi:10.1016/0165-0173(91)90012-W.

[39] M. Feldman, P. Walker, J.L. Green, K. Weingarden, Life events stress and psychosocial factors in men with peptic ulcer disease: a multidimensional case-controlled study, Gastroenterology. 91 (1986) 1370-9. doi:10.1016/0016-5085(86)90189-7.

[40] M.P. Jones, The role of psychosocial factors in peptic ulcer disease: Beyond Helicobacter pylori and NSAIDs, J. Psychosom. Res. 60 (2006) 407-412. doi:10.1016/j.jpsychores.2005.08.009.

[41] T. Furuta, S. Baba, M. Takashima, H. Futami, H. Arai, M. Kajimura, H. Hanai, E. Kaneko, Effect of Helicobacter pylori infection on gastric juice pH, Scand. J. Gastroenterol. 33 (1998) 357-63. http://www.ncbi.nlm.nih.gov/pubmed/9605256.

[42] R. Doll, F.A. Jone, M.M. Buckatzsch, F.A. Jones, M.M. Buckatzsch, Occupational factors in the aetiology of gastric and duodenal ulcers with an estimate of their incidence in the general population, Spec. Rep. Ser. Med. Res. Counc. (G. B). 276 (1951) 1-96. http://www.ncbi.nlm.nih.gov/pubmed/14798563.

[43] M.N. Peters, C.T. Richardson, Stressful life events, acid hypersecretion, and ulcer disease, Gastroenterology. 84 (1983) 114-9. https://www.ncbi.nlm.nih.gov/pubmed/6847839.

[44] W.H. Bresnick, C. Rask-Madsen, D.L. Hogan, M.A. Koss, J.I. Isenberg, The effect of acute emotional stress on gastric acid secretion in normal subjects and duodenal ulcer patients., J. Clin. Gastroenterol. 17 (1993) 117-22. http://www.ncbi.nlm.nih.gov/pubmed/8409313.

[45] Y. Elitsur, Z. Lawrence, Non-Helicobacter pylori related duodenal ulcer disease in children, Helicobacter. 6 (2001) 239-243. doi:10.1046/j.1523-5378.2001.00034.x.

[46] J.Q. Huang, S. Sridhar, R.H. Hunt, Role of Helicobacter pylori infection and non-steroidal anti-inflammatory drugs in peptic-ulcer disease: A meta-analysis, Lancet. 359 (2002) 1422. doi:10.1016/S0140-6736(02)07273-2.

[47] A. Schmassmann, Mechanisms of ulcer healing and effects of nonsteroidal antiinflammatory drugs, Am. J. Med. 104 (1998) 43S-51S; discussion 79S-80S. http://www.ncbi.nlm.nih.gov/pubmed/9572320.

[48] D.Y. Graham, Y. Yamaoka, H. pylori and cagA: Relationships with gastric cancer, duodenal ulcer, and reflux esophagitis and its complications, Helicobacter. 3 (1998) 145151. doi:10.1046/j.1523-5378.1998.08031.x.

[49] E.J. Rauws, G.N.J. Tytgat, Helicobacter pylori in duodenal and gastric ulcer disease, Baillière's Clin. Gastroenterol. 9 (1995) 529-547. doi:https://doi.org/10.1016/09503528(95)90047-0.

[50] Y. Yamaoka, T. Kodama, M. Kita, J. Imanishi, K. Kashima, D.Y. Graham, Relation between clinical presentation, Helicobacter pylori density, interleukin 1 beta and 8 production, and cagA status, Gut. 45 (1999) 804-811. http://www.pubmedcentral.nih.gov/articlerender.fcgi?artid=1727763\&tool=pmcentrez\&ren 
dertype $=$ abstract.

[51] E. Roma, J. Panayiotou, Y. Kafritsa, C. Van-Vliet, A. Gianoulia, A. Constantopoulos, Upper gastrointestinal disease, Helicobacter pylori and recurrent abdominal pain, Acta Paediatr. 88 (1999) 598-601. http://www.ncbi.nlm.nih.gov/pubmed/10419241.

[52] P. Bytzer, P.S. Teglbjaerg, Helicobacter pylori-negative duodenal ulcers: prevalence, clinical characteristics, and prognosis-results from a randomized trial with 2-year followup, Am. J. Gastroenterol. 96 (2001) 1409-1416. doi:10.1111/j.1572-0241.2001.03774.x.

[53] G. Meucci, R. Di Battista, C. Abbiati, R. Benassi, L. Bierti, A. Bortoli, E. Colombo, A. Ferrara, A. Prada, G. Spinzi, R. Venturelli, R. de Franchis, Prevalence and risk factors of Helicobacter pylori-negative peptic ulcer: a multicenter study, J. Clin. Gastroenterol. 31 (2000) 42-47. doi:10.1097/00004836-200007000-00010.

[54] B. Sivri, Review Article: Trends in peptic ulcer pharmacotherapy, Fundam. Clin. Pharmacol. 18 (2004) 23-31. doi:10.1111/j.1472-8206.2004.00203.x.

[55] J.W. Freston, Review article: role of proton pump inhibitors in non-H. pylori-related ulcers, Aliment. Pharmacol. Ther. 15 Suppl 2 (2001) 2-5.

http://www.ncbi.nlm.nih.gov/pubmed/11556873.

[56] L. Laine, R. Estrada, M. Trujillo, K. Knigge, M.B. Fennerty, Effect of proton-pump inhibitor therapy on diagnostic testing for Helicobacter pylori, Ann. Intern. Med. 129 (1998) 54750. http://www.ncbi.nlm.nih.gov/pubmed/9758575.

[57] S. Levenstein, C. Prantera, V. Varvo, S. Spinella, M. Arcà, O. Bassi, Life events, personality, and physical risk factors in recent-onset duodenal ulcer: a preliminary study, J. Clin. Gastroenterol. 14 (1992) 203-210. doi:10.1097/00004836-199204000-00005.

[58] J.H. Kurata, A.N. Nogawa, D.E. Abbey, F. Petersen, A prospective study of risk for peptic ulcer disease in Seventh-Day Adventists, Gastroenterology. 102 (1992) 902-909. doi:S0016508592001215 [pii].

[59] K. Ellard, J. Beaurepaire, M. Jones, D. Piper, C. Tennant, Acute and chronic stress in duodenal ulcer disease, Gastroenterology. 99 (1990) 1628-32. http://www.ncbi.nlm.nih.gov/pubmed/2227279.

[60] S. Levenstein, C. Prantera, M.L. Scribano, V. Varvo, E. Berto, S. Spinella, Psychologic predictors of duodenal ulcer healing, J. Clin. Gastroenterol. 22 (1996) 84-89. doi:10.1097/00004836-199603000-00002.

[61] M. Joëls, H. Karst, D. Alfarez, V.M. Heine, Y. Qin, E. Van Riel, M. Verkuyl, P.J. Lucassen, H.J. Krugers, Effects of chronic stress on structure and cell function in rat hippocampus and hypothalamus, Stress. 7 (2004) 221-231. doi:10.1080/10253890500070005.

[62] Y.M. Ulrich-Lai, H.F. Figueiredo, M.M. Ostrander, D.C. Choi, W.C. Engeland, J.P. Herman, Chronic stress induces adrenal hyperplasia and hypertrophy in a subregionspecific manner, AJP Endocrinol. Metab. 291 (2006) E965--E973. doi:10.1152/ajpendo.00070.2006.

[63] A.J. Blair, M. Feldman, C. Barnett, J.H. Walsh, C.T. Richardson, Detailed comparison of basal and food-stimulated gastric acid secretion rates and serum gastrin concentrations in duodenal ulcer patients and normal subjects., J. Clin. Invest. 79 (1987) 582-587. doi:10.1172/JCl112850.

[64] J.B. Kirsner, W.L. Palmer, Seminars on gastrointestinal physiology: the problems of peptic ulcer, Am. J. Med. 13 (1952) 615-639. https://doi.org/10.1016/00029343(52)90028-4.

[65] J.P. Van Gigch, Book review: Design of the modern inquiring system-i. r. descartes (1596-1650), Syst. Res. Behav. Sci. 5 (1988) 267-269. 